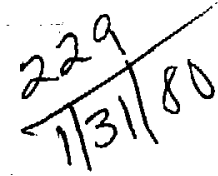

\title{
ELECTRICAL DISCHARGE IN GASES- A TECHNIQUE FOR DETECTING METAL ANOMALIES
}

David E. Lord

June 6, 1979

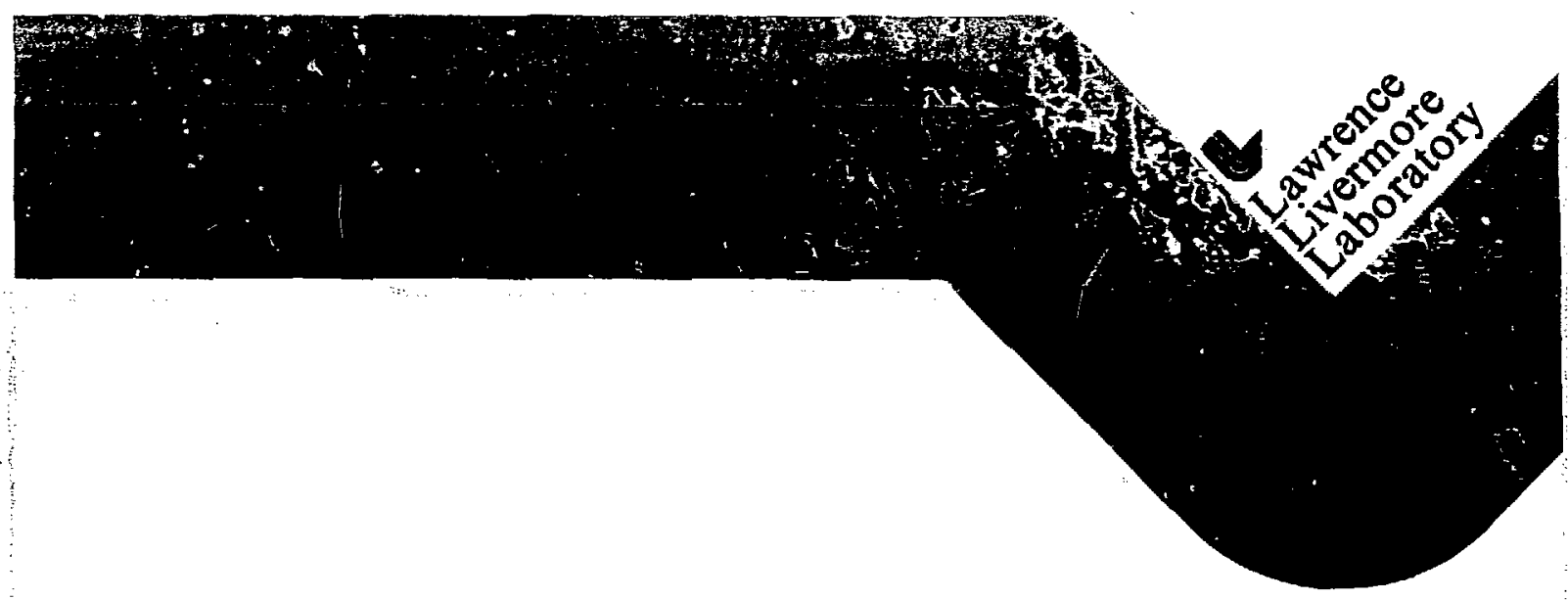




\title{
ELECTRICAL DISCHARGE IN GASES- A TECHNIQUE FOR DETECTING METAL ANOMALIES
}

\author{
David E. Lord
}

Manuscript date: June 6, 1979

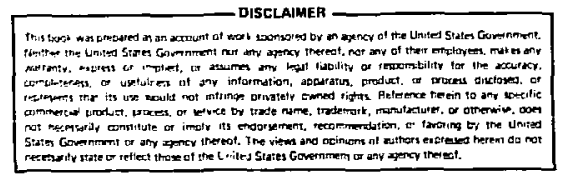

\section{LAWRENCE LIVERMORE LABORATORY} University of California $\cdot$ Livermore, California $\cdot 94550$ 


\section{CONTENTS}

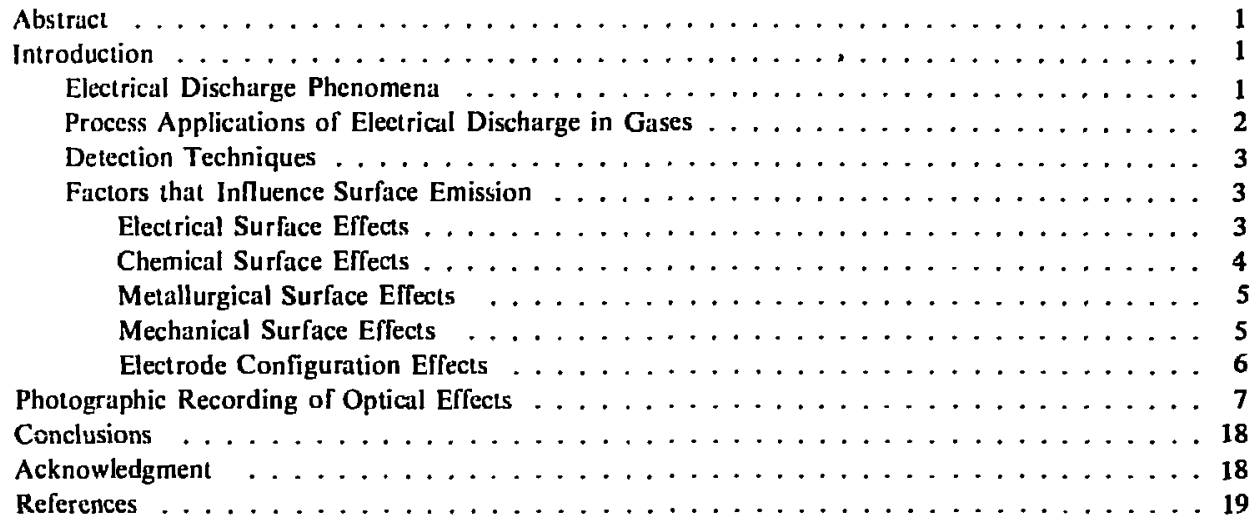




\title{
ELECTRICAL DISCHARGE IN GASES- A TECHNIQUE FOR DETECTING METAL ANOMALIES
}

\begin{abstract}
Optical ionization effects in gases appear to be very sensitive indicators of nonuniformities caused by contamination, deformation, and other factors affecting a metal surface. These optical effects are influenced by surface electron emission, which is influenced in turn by the chemical, metallurgical, and mechanical condition of the metal surface. Based on these effects, a general technique for inspection of critical parts that is fast, inexpensive, nondestructive, and not limited by size or geometry is presented. Ionization effects that reveal nonuniformities and were recorded with standard photographic equipment are shown.
\end{abstract}

\section{INTRODUCTION}

This report provides a brief history of the electrical discharge phenomena in gases, the related industrial processes, and the practical, modern use of optical ionization effects to detect metal nonuniformily. To assess the causes of the various optical effects derived from the factors influencing the electrical surface behavior, some background in electrical rhemical, metallurgical, and mechanical surface effects is needed, as is an understanding of electrode configuration effects. This report presents the necessary background and the photographically recorded optical effects that have resulted from a two-year study. Though only a beginning, the study has produced enough evidence for the interpretation of these optical effects in terms of surface characteristics to warrant further investigation.

\section{ELECTRICAL DISCHARGE PHENOMENA}

The mid-191h century saw the advent of a simple device called a discharge tube, which contained a cathode and an anode separated by some distance in an imperfectly evacuated, nonconducting (glass) container. Voltage applied across the electrodes produced a current flow in the residual gas. When the voltage became high enough, luminescence resulted.
Since then, many studies have examined the controlling factors of gas pressure (number of atoms present), electrode separation, electrode geometry, voltage, and current. Voltage and current can be either dc or ac, extending even to radio frequencies.

The first optical indications in a discharge tube occur in the region aptly named the glow discharge, and there are several glow regions between the electrodes. For our purposes, the most important are the negative glow region (the brightest) and the cathode glow (next brightest). There is also a positive column glow, which is visible, but very faint by comparison. Each region has a characteristic color for a given gas. A sampling of these colors is given in Table 1 for a few common gases.

If pressure is decreased below about 1 Torr, the negative glow region expands, pushing the positive column and eventually the negative glow to extinction at the anode. An increase in pressure to about 100 Torr causes the negative glow to cover the cathode while the positive column elongates and becomes nearly invisible in a pinched central-axis position.

The discussion so far has assumed flat metal electrodes and uniform electric fields. If one electrode has a protrusion (sharp point), however, coronal discharge will occur at a certain voltage. Defined as a discharge in a nonuniform electric 
TABLE 1. Characteristic colors of various glow regions in a discharge tube for some common gases, from Ref. 1.

\begin{tabular}{llll}
\hline \multicolumn{1}{c}{ Gas } & Cathode glow & Negative glow & Positive column giow \\
\hline $\begin{array}{l}\text { Nitrogen (Air) } \\
\text { Oxygen }\end{array}$ & Pink & Blue & Pink \\
Hydrogen & Red & Yellow-white & $\begin{array}{l}\text { Pale yellow and } \\
\text { pink center } \\
\text { Helium }\end{array}$ \\
Argon & Brown-red & Pale Blue & Red \\
Nenn & Red & Green & Red-violet \\
Most hydrocarbons & Pink & Dark blue & Dark red \\
- & Yellow & Orange & Dark red
\end{tabular}

${ }^{a}$ From our work.

field, the term coronal discharge is usually used only at the higher pressures ( $\sim \mathrm{atm}$ ). Sharp points or corners distort the electric field, thereby allowing the gas to break down at lower applied voltages because of the higher voltage gradient from point or edge to the opposite electrode.

High-frequency breakdown is another important phenomenon. Below a few $\mathbf{~ k H z}$, the breakdown is similar to the direct-current effects. However, as the frequency increases above a few $\mathrm{kHz}$, the ionized gas particles move too slowly to traverse the electrode separation before the polarity reverses. These charged particles then remain in the gas a long time, and each accounts for many ionizing collisions.

For further discussion of electrical discharge phenomena, the reader is referred to Refs. 1 and 2, which are very readable books on this topic.

\section{PROCESS APPLICATIONS OF ELECTRICAL DISCHARGE IN GASES}

Probably the most widespread modern cousin of the discharge tube is the fluorescent light. Another notable gas discharge device is the gas laser. A number of electrical/electronic rectifier devices are in the family, as are electrophoresis apparatus and such materials processing applications as welding, nitriding, and even plastics processing. ${ }^{3,4}$ Sputtering processes are usually included in such applications. These find wide use in modern industry. ${ }^{5}$
The new field of ion implantation could be considered a related process since the ion source is a glow discharge. Ion implantation in semiconductor technology is used more and more because of the better yield of circuits over the diffusion processes. With ion injection, the new material does not form in thermodynamic equilibrium. Therefore, chemical solubilities are bypassed, and new materials can be made.

Ionizations produced in a glow disct :rge have average electron energies in the $1-$ to $10-\mathrm{eV}$ range with electron densities of $10^{9}$ to $10^{12} \mathrm{~cm}^{-3}$. Usual electron-to-bulk gas temperature ratios range from 10 to 100 . Because thermal equilibrium does not exist, energetic electron effects (ionization) can accomplish various chemical or mechanical reactions while the gas and electrode materials remain relatively cool. As a result, there is little or no damage to materials with low melting points.

On the other hand, thermal equilibrium is achieved in arcs or plasma jets, and temperatures can reach $5000 \mathrm{~K}$ or more, suitable for working refractory metals and ceramics.

One industrial process that bears closely on our subject is called ionitriding. ${ }^{6-8}$ Discovered in the United States and developed in Germany, ionitriding hardens steel surfaces for wear enhancement by introducing nitrogen atoms to a maximum $10-\mu \mathrm{m}$ depth. The glow produced in the vacuum chamber ( 1 to $10 \mathrm{Torr}$ ) by a 500 - to $1000 \mathrm{~V}$ power supply completely covers the parts. Parts that weigh upwards to 1.5 ton are now routinely processed worldwide. 


\section{DETECTION TECHNIQUES}

Basically, all the industrial processes discussed above use electrical discharge to change material characteristics. For the purpose of detection, reading a metal electrode's gaseous discharge reveals its characteristics. Thus, in a sense, we turned the industrial processes around. To avoid sputtering, ion implantation, or such processes, we control voltage, time of exposure, and gaseous atmosphere.

Discharge current-measuring techniques have also been suggested as ways to detect contamination or impurities on metal surfaces. ${ }^{9,10}$ However, these techniques are similar to those used for measuring the work function of a surface. ${ }^{11}, 12$ The devices generally have small electrode area and spacing and must scan the part's surface to present a definitive overall picture. Because both techniques are affected by the same factors that influence surface emission (discussed below), the optical whole-body photographic techniques presented here are probably better at detecting nonuniformities in large or complex-geometry parts and are certainly much simpler to use than discharge currentmeasuring techniques.

\section{FACTORS THAT INFLUENCE SURFACE EMISSION}

\section{Electrical Surface Effects $1,2,13,14$}

The cffects of electrode material properties on the gaseous ionization potentials and current flow in a discharge tube are well known if not well understood. Electron emission and absorption by metal surfaces have been studied for a century. The diode (a one-way current how device) operates on the principle that the cathode material is a much better emitter of electrons than the anode material. To this end, a coating of certain oxides (usually barium and strontium) may enhance emission. Tungsten impregnated with thoria is also used in various electronic emitter applications.

The probability of electron escape from a metal surface to the adjacent region in a gaseous medium is controlled by the material's work function $\phi$, the minimum energy an electron must have to escape the metal's surface barrier. The work function is influenced by a volume effect and a surface effect. The volume effect depends on the electron energy inside the material, not on the emitter surface characterist ics. The surface effect is sensitive to intentional or accidental contamination and to various mechanical and metallurgical conditions.

The mechanisms of electron emission from a surface are generally divided into groups based on the causative factor. For instance, thermionic emission requires relatively high surface temperature $(\sim 2500 \mathrm{~K})$ to be significant for a pure metal. In a discharge tube with a heated cathode, the anode voltage can be increased to a saturation level. Increasing the voltage further produces no increase in current, and the system is temperature limited. The current will increase if the cathode temperature is increased. This current is related to other factors for a clean metal surface by the Richardson-Dushman equation

$$
I=A T^{2} e^{-\phi / k T}
$$

where

$$
\begin{aligned}
& \mathbf{T}=\text { absolute cathode temperature } \\
& \mathbf{A}=\text { constant } \\
& \phi=\text { work function } \\
& \mathbf{k}=\text { Boltzmann's constant. }
\end{aligned}
$$

The current is controlled by the temperature and the work function.

Sufficiently energetic light (photons) striking a metal surface can displace electrons. Such photoemission (external photoeffect as distinguished from photoconductive and photovoltaic effects) was observed almost a century ago and explained later by Albert Einstein with the equation

$$
\mathrm{E}=h w-e w
$$

where

$$
\begin{aligned}
& E=\text { emission energy of the photoelectron } \\
& e=\text { electron charge } \\
& h=\text { Planck's constant } \\
& y^{\prime}=\text { frequency of the photon. }
\end{aligned}
$$

Emission, which occurs only if the photon energy exceeds the work funtion, is proportional to the light intensity. Such emission is highly dependent on the character of the surface. 
Secondary electron emission results from energetic electrons striking the metal surface. The electrons generally fit into one of three categories:

- Elastically reflected electrons

- Inelastically reflected electrons

- Secondary electrons ( 10 eV).

The energy of secondary electrons is independent of primary electron energy.

The secondary emission coefficient is defined as

$$
i=\frac{A+B+C}{I}
$$

where $A, B$, and $C$ are all defined flows for the three categories above, and $I$ is the primary current.

The secondary emission peaks as the primary energy increases. This peak is expressed as $\delta_{\max }$ at the corresponding primary energy (volts).

Field emission relies upon high elestric lields close to the cathode to produce a low work function and, therefore, a large emission. The lowered work function is an exponent in Eq. (1); hence, the flow increase can be large even at somewhat lower temperatures.

The Schottky effect is a combination of thermionic and field emissions. It holds only for relatively high temperatures and is usually accounted for by substituting a modified work function $\phi^{\prime}$ for $\phi$ in Eq. (1). This $\phi^{\prime}$ is also greatly influenced by surface characteristics.

Field emission can lower the potential barrier by electric fields alone (no heating) and allow the tunnel effect or autoelectron emission to take place. The effect of an intense external field is to lower the barrier potential below the energy level of the top band of valence electrons. Electrons can then jump the barrier. The high field potentials enhance the probability of this happening. Autoelectronic current I can be described by the Fowler-Nordheim equation

$$
\mathbf{I}=\mathbf{A E}^{2} \mathrm{e}^{-\mathbf{B} / \mathbf{E}}
$$

where

$$
\begin{aligned}
& A=\mathbf{a} \text { function of } \phi \\
& B=\mathbf{a} \text { function of } \phi \\
& E=\text { field strength at surface. }
\end{aligned}
$$

Note that the equation is similar to the Richardson-Dushman equation with electric field strength substituting for temperature. The tunnel effect is therefore independent of temperature and strongly dependent on field strength. Current is limited by the conductivity of the material, which in metals allows high current densities. As in the other emission modes, the surface exerts a strong influence on emission characteristics.

These emission modes have a common thread. All are controlled by the work function or equivalent term that is controlled, in turn, by surlace conditions of chemical, mechanical, and metallurgical natures. The equations are intended to represent clean surfaces only. Addition of other materials or compounds can induce orders-ofmagnitude changes (increases and decreases) in emission.

If all the causative factors are present, the total now will be the sum of the individual flows. In our investigation the cathode is cold; no heating other than that inherent in the electron collisions is applied. Thus, the major contribution is from the tunnel or autoelectron effect. In the case of corona (strong light generation), there may be significant photoelectric contribution, and some secondary emission is always present in most cases.

\section{Chemical Surface Effects $12,14,15$}

Adsorption of foreign atoms on a clean metal surface may modify the configuration of the surface atoms and/or form a dipole layer. Generally, electropositive adsorbates reduce the metal's work function; electronegative adsorbates increase it. The adsorbate atoms may be of several kinds and interact in such a complex manner that the net effect may not follow the general statement for single kinds of atom layers. The effects of multiple adsorbed materials on clean surfaces is presently of keen interest in electron emitter research.

A commercial example of an electropositive layer used to decrease the work function of the cathode is that of thoriated tungsten. Another is the oxide cathode using barium and strontium. Both are processed or activated to produce very thin surface layers of the metal components. This might be considered purposeful contamination as opposed to the accidental kind. The nonuniformities of both are detectable. For a given electrode, in our coldcathode discharge tube, an area of different quantity and/or kind of adsorbate would produce a difference in brightness of the ionized gas near the electrode. Because most ionized gases are remarkably 
transparent, the bright (or dull) areas are quite visible compared to the general sufface illumination.

If the adsorbate is volatilized by the electronbombardment-produced surface temperature, the ionized gas not only changes in brilliance but also in color. The changing chemistry of the ionized gas close to the adsorbate is responsible for the change in color.

Chemically reacted (or unreacted) surface areas can be distinguished by their different brilliance as can areas of different chemical composition of the substrate, since the substrate material does influence the work function to some degree.

\section{Metallurgical Surface Effects ${ }^{12,14,16}$}

The potential barrier of the surface is sensitive to the crystallographic orientation of the emitting surface. This effect is thought to arise from a dipole charge-smoothing layer, positive outside the surface and negative inside, that reduces the work function. This smoothing or electron redistribution on a surface depends on the surface's atomic conliguration, that is, its crystallographic plane. This smoothing charge opposes the interior charge that tends to coat all surface crystallographic planes evenly and to increase the work function. The work function is greater for close-packed planes than for high-index planes. The surfaces of high work function exhibit low surface energies and vice versa.

In alloys, ordering affects electron emission. There is a discontinuity in the RichardsonDushman equation at the ordering temperature.

That a metal surface develons a pattern of deformation when the substrate is deformed leads to some interesting speculation as to the possiblity of reading the surface to assess the metal's internal stress state. The surface accurately shows the integrated net plastic displacements. If the plastic strain is not uniform, the surface will reflect this. This surface area generation requires additional energy, such as chemical and mechanical work, beyond the bulk deformation energy.

The external surface does not appear to influence elastic deformation of a metal. The elastic deformation, however, is reflected in the surfacelayer deformation.

The metal surface ple:s a large part in the generation of several failure mechanisms, notably, metal fatigue caused by cyclic loading and stress concentrations, which generate slip bands. Such accumulated deformations can then grow to serious proportions. The surface favors plastic deformations and local stress concentrations that initiate flaw nucleation mechanisms. The debris layer $(\sim 100 \mu \mathrm{m})$ generated by early plastic deformations affects the applied stress according to Kramer's equation

$$
\sigma_{n c t}=\sigma_{a}-\sigma_{i}-\sigma_{s}
$$

where

$$
\begin{aligned}
& \sigma_{\mathrm{a}}=\text { applied stress } \\
& \sigma_{\mathrm{i}}=\text { internal resistive stress } \\
& \sigma_{\mathrm{s}}=\text { surface resistive stress. }
\end{aligned}
$$

This surface stress in pure metals usually disappears within hours after removal of the applied stress. The surface stress, however, can be an appreciable part of the net stress. In many materials, removal of the surface debris layer signilicantly affects the failure stress.

\section{Mechanical Surface Effects 1,2,16}

Not all observed optical effects stem from electron emission. Because the generated light in the ionized gas is reflected, absorbed, and scattered by the surface configurations, optical observation is a combination of effects, some separable, some not. We can separate the work-function effects from the reflected light if certain factors are controlled; however, in most cases the effects reinforce each other.

The texture of a metal electrode can be defined in terms of macro and micro regimes. Basically, the texture is the surface finish, which comes from a deformation of some kind. Machining is one deformation that usually leaves a smoother finish than the original, in several degrees up to a polished surface. Treatment of this surface by chemically active solutions can improve the finish or, if carried too far, can produce porosities. Other surface deformations arise from mechanical deformation of the substructure, either from increased stress or stress relief. We can consider a deposit of foreign material, intentional or not, chemically active or not, a deformation of the original surface. In all of these processes, surface properties and the work function are changed by chemical, metallurgical, and/or mechanical means.

The breakdown or light-generation capability of such a disturbed area depends on the factors that 
affect discharge-tube operation (pressure, electrode separation, etc.) but mainly on the two regimes of glow and corona. These are very different if not opposite in their interactions with materials.

Surface roughness, whether caused by any of the deformations or lack of them, influences the work function of the surface and therefore the light generation capability near it. There is a simple geometrical explanation for the reduced emission of rough surfaces: though the actual surface area is larger than a smooth surface, the reabsorption of emitted electrons is larger yet.

This same rough surface tends to absorb and/or scatter incident light and appears darker than surrounding areas. The appearance of this surface can be altered by changing the angle(s) of the incident light. Shadows can be effectively eliminated by the multisource ion-generated light. The viewing angle with respect to the incident light also plays an importart part in texture analysis and pattern recognition.

Many of these textures or patterns are generated by the interactions of surface layers and substrates and are recognizable. The visibly deformed surface layers then reflect conditions that preexisted or exist in the substrate. Analogies and examples abound. Stevens ${ }^{17}$ points out a number of patterns that correspond nicely to some of our observed metal-surface textures or patterns. One that is typical of shrinking coatings on strong substrates matches one of our plated specimens (Fig. 7) and is easily recognizable. Shrinking films not only shrink, they flow, minimizing work ana area. If only surface tension (elastic) were present, the angles between cells would approach $120^{\circ}$. The flow process reduces this angle to around $75^{\circ}$ for pure flow processes. Process combinations produce intermediate angles.

Stevens ${ }^{17}$ points out that patterns and textures in such things as tree bark are responses to internally generated stresses. The analogy to our various surface layers, whether generated by machining (the Bielby layer) or internal strain (the debris layer), seems excellent. Internal stresses acting on a surface layer of different properties leave a tell-tale texture or pattern that may be interpreted qualitatively if not yet quantitatively. Another way of looking at the situation is that the "skin" of the metal is a membrane that follows the substrate strains. The skin may then be interpreted if its properties are known, much as the modern strain gage senses sur- face strains that are interpreted in terms of internal strains.

Thus, mechanical deformations produce patterns that are at least recognizable, if not analyzable.

\section{Electrode Configuration Efrects 1,2}

Corona is defined as gaseous breakdown in nonuniform electric fields. This nonuniformity can be generated by a nonuniform electrods, particularly one with sharp protrusions or edges. The effect is accentuated by high pressures. A current limiter is advisable under such conditions-either internal or external to the system. Corona exists on a microscale as well as the meteorological one, from such disparate surfaces as the ridges of a finely linished machined surface gage to a lightning rod on a skyscraper.

Glow can exist alongside corona, particularly in the high-pressure (up to $\sim 1 \mathrm{~atm}$ ) range. Even with very nonuniform electrodes, the corona can be removed by separating the electrodes and lowering the pressure to make the various current paths more uniform and the field gradients, though deformed (curved), reasonably uniform. Interior surfaces then become the brightest. As distinct from corona, the glow eschews corners and edges and intensilies in holes and concave configurations. It likes to crawl into holes and cracks, even into very complex electrode configurations. The glow appears to want to evenly coat a uniform electrode surface inside and out.

Current limiters are not usually necessary for high-impedance glow systems. For instance, an electrode of $\sim 100 \mathrm{~cm}^{2}$ and operating at $100 \mu \mathrm{m} \mathrm{Hg}$ pressure, $1000 \mathrm{~V}$ and at $1 \mathrm{kHz}$, uses about $150 \mathrm{~W}$ or draws about $150 \mathrm{~mA}$. Under these conditions, the glow completely covers the electrode surface.

Glow is a gentle illumination that spreads along a surface and exhibits colors characteristic of the gas. Illumination by glow discharge tends to be shadowless if it approaches uniformity. Otherwise, the brightest areas can create some shadows. However, such illumination is much more shadowless than single-source illumination. Corona is very intense compared to glow discharge and is usually characterized by a strong white light concentrated along the breakdown paths. The fact that glow and corona interact differently with given electrode configurations provides an interesting tool for interpretation of electrode interactions. 


\section{PHOTOGRAPHIC RECORDING OF OPTICAL EFFECTS}

Normal color photography using macro and normal lenses is probably the best, least expensive method for recording optical ionization effects. If dynamic recording is justified, then a low-light coior video system is the answer. In either case, the results are spectacular, colorful, and even useful.
In this study we used two general configurations, labeled $A$ and $B$ in Fig. 1. Configuration $A$ is the discharge tube in its usual form, which is operated at low pressures in an easily controlled gas environment with relativeiy large electrode spacing. Our version of this time honored apparatus is
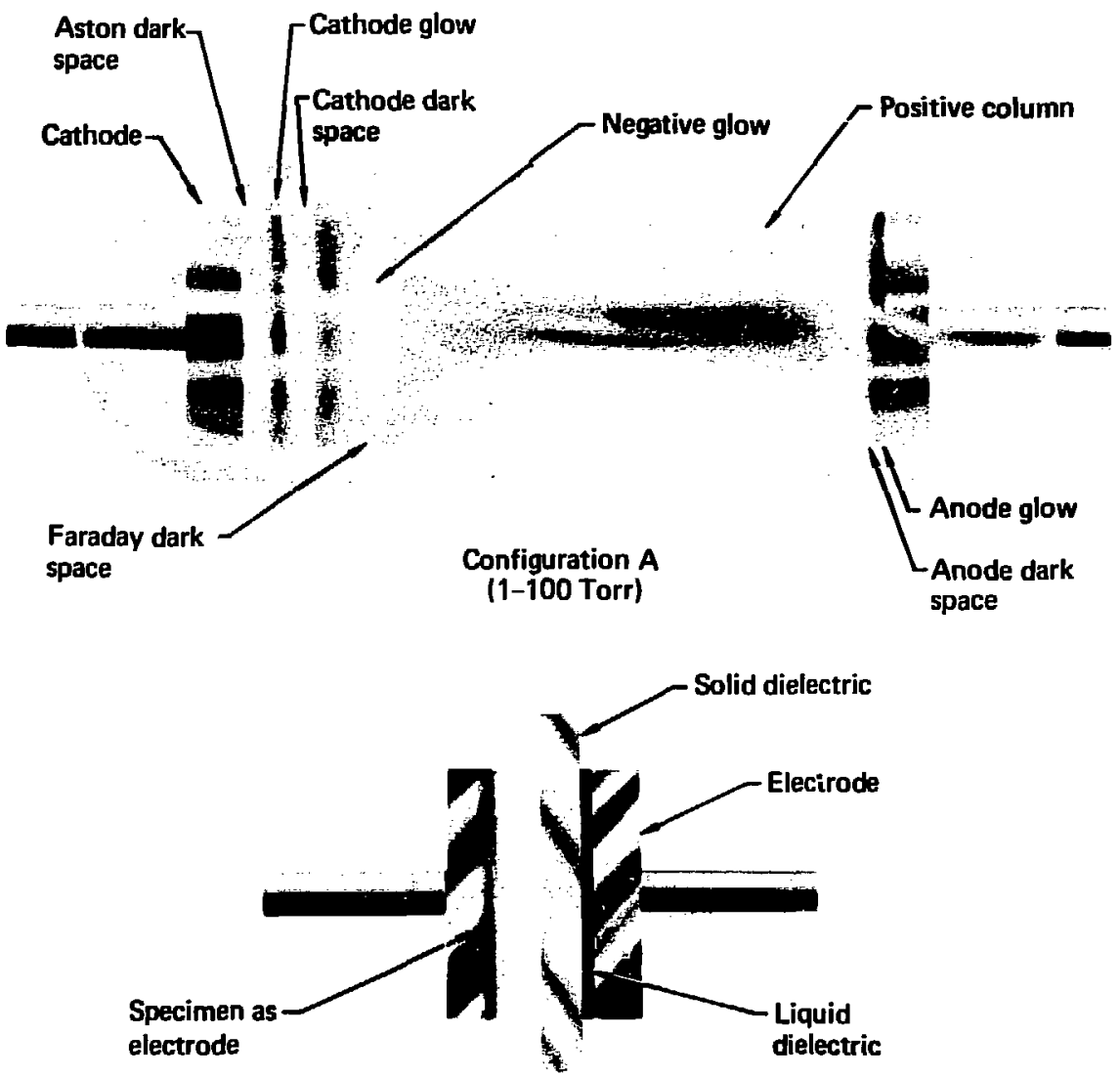

Configuration B

(atmosphere)

FIG. 1. Two general configurations used to study electrical discharge. Configuration $A$ is a normal discharge tube operated at reduced pressures with various gases and large electrode spacing. The flat-electmde confignration B, usually operated at atmospheric pressure, produces both glow and corona. 


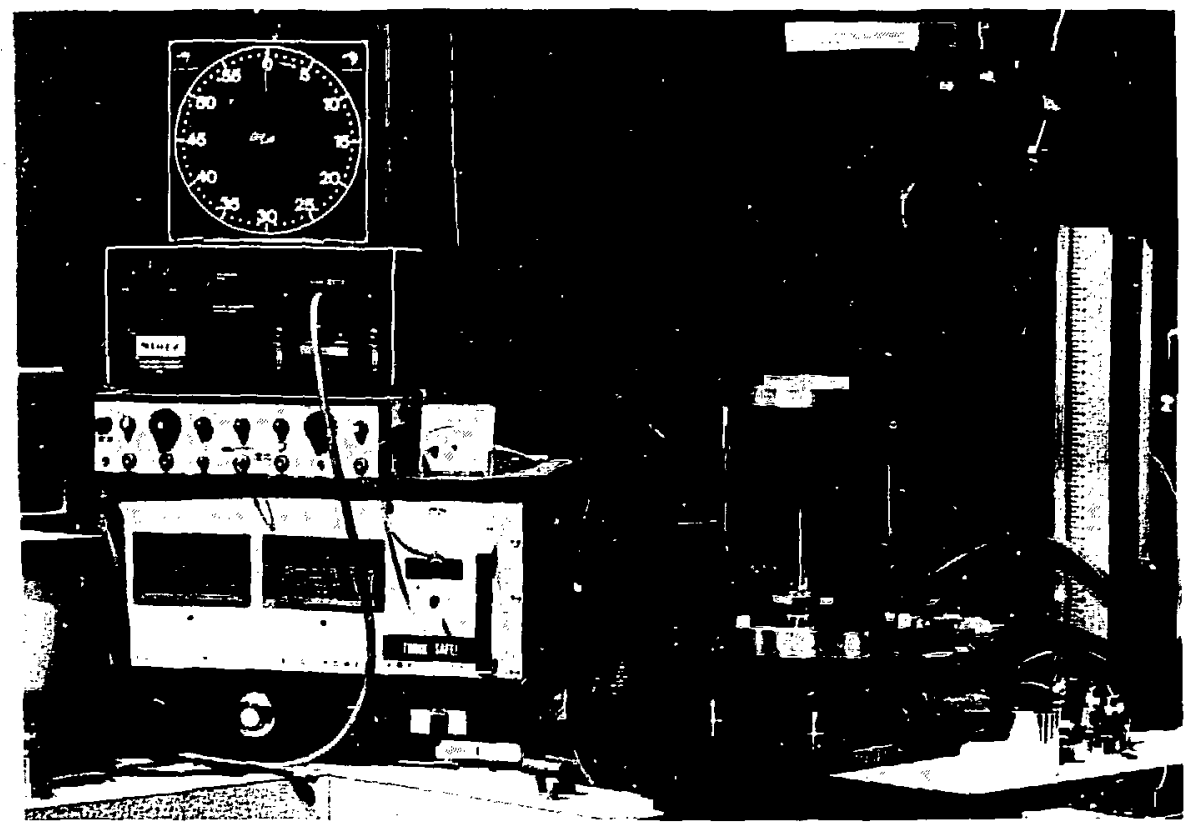

FIG. 2. Our experimental version of configuration A has a 20 -cm-diam, vertically mounted glass discharge chamber, shown on the right. The waveform generator and amplifier are on the left, the transformer in the center.

shown in Fig 2. We added some conveniences to the busic structure. The glass tubing $(20-\mathrm{cm}$ diam) is mounted vertically on a gasketed aluminum end plate, which has a motor-driven chuck cxtending into the chamber. This set-up allows easy change of the cathode structure plus rotational observation of all surfaces. The anode is a copper mesh that can be manually moved to vary electrode spacing inside the supporting glass tubing. The anodes-both copper mesh and gasketed aluminum end plate-have central open areas of $\sim 8-\mathrm{cm}$ diam that allow viewing of the top of the cathode. A circular glass plate with gasket seals the aluminum anode.

Configuration $B$ is the usual one for flat cathodes when a combination of corona and glow is desired (Fig. 3). Normal operation is at atmospheric pressure. The solid dielectric (usually $1.5-\mathrm{mm}$
Kodak slide glass) both limits current and controls spacing. We gencrally use a conductive tin-oxidecoated glass anode to allow top viewing of the cathode surface. In some cases, a transparent diclectric liquid is used to suppress unwanted gaseous ionizations in the dielectric-anode space. Stacked vertically inside the glass tubing, the glass anodes brotact the operator.

Both configurations have a plexiglas cover to preveni accidental contact with the external electrodes. The driving system for both configurations is a function generator, a relatively high-powered, 300-W stereo amplifier, and a heavy iron-core transformer rated at $10 \mathrm{kV}, 10 \mathrm{kHz}$, and $500 \mathrm{~W}$.

The optice l effects can be seen by the unaided humani eye except for the short-pulse regime, which is sometimes us ad in configuration-B systems in 


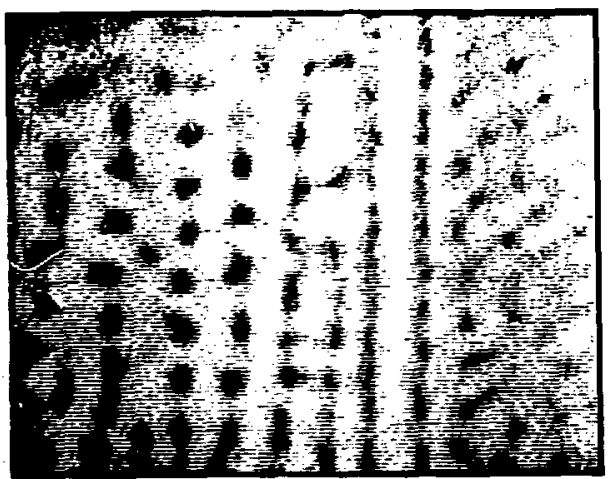

(a)

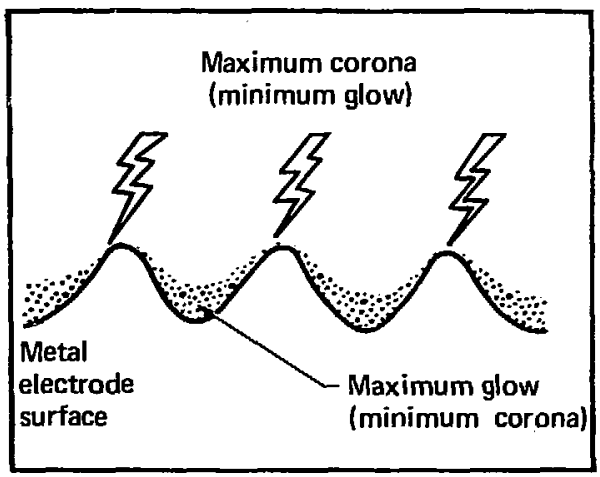

(b)

FIG. 3. An ionization-field photograph of a $0.75-\mu \mathrm{m}-$ surface-finish gage taken with configuration $\mathrm{B}$ ieveals regions of microcorona (dark areas in (a)) and glow. Both phenomena are depicted in (b).

which the subject cathode is placed direclly on film or photographic paper. Recording is easy with the transparent (conductive-glass) anode and transparent dielectric of configuration $B$, which allow use of extarnal conventional film and video cameras. The glow system (configuration $\mathrm{A}$ ) is usually used in a continuous or repeated mode of voltage application. External conventional photographic systems, both film and video types, can be used for recording purposes. The sensitive low-light video cameras (both color and black-andwhite) are particularly useful for recording dynamic phenomena on videotape.

Figure 3a shows the microcorona combined with glow, as cispict in Fig. 3b. The corona follows the high points in machined ridges of a 0.75 $\mu \mathrm{m}$-surface-finish gage. This photograph was made from a low-light videotape of the $B$ configuration system with transparent dielectric and anode. Note that Figs. 3a, 6, 7, and 13a are negative prints for reasons of improved contrast and clarity. As a result, areas that appeared light during the experiments appear dark in the figures.

Figure 4a is a copper tee fitting, $\sim 25 \mathrm{~mm}$ in diameter, photographed in the configuration $A$ system by conventional $35 \mathrm{~mm}$ camera and color film in combined neon gas glow and fluorescent room light. The glow completely covers the stirface inside and out. It becomes weaker at convexities (external corners) and is reinforced at concavities (fillets, or internal corners).

Figure $4 \mathrm{~b}$ illustrates the emission effects of a $v$ Jatilized chemical adsorbate en the surface of the copper tee-residue from hydrochloric acid, in this case. The photograph was made by the light of neon gas. Such systems tend to be self-cleaning as more and more of the volatile material is removed; however, depending on the adsorbate, some residue usually remains and afiects emission characteristics.

The sequence of photographs in Fig. 5 shows the effects of a very familiar chemical adsorbate-the residue of the bare human hand. All of the photographs were taken on $35 \mathrm{~mm}$ color film with the $A$ system in neon gas. Figure $5 a$ is a clean aluminum prism ( 4 by 30 by $200 \mathrm{num}$ ) photographed by fluorescent room light. Figure 5 b shows the ionized gas glow of the uniformly clean aluminum prism. Figure 5c shows the emission changes wrought by a bare human thumb. Figure $5 \mathrm{~d}$ shows the opposite side of the prism and the effects of the bare human index finger plus smudges. Subsequent attempts to clean this prism met with varying degrees of success as evidenced by the ion photos. The hand residues after cleaning were not visible to 


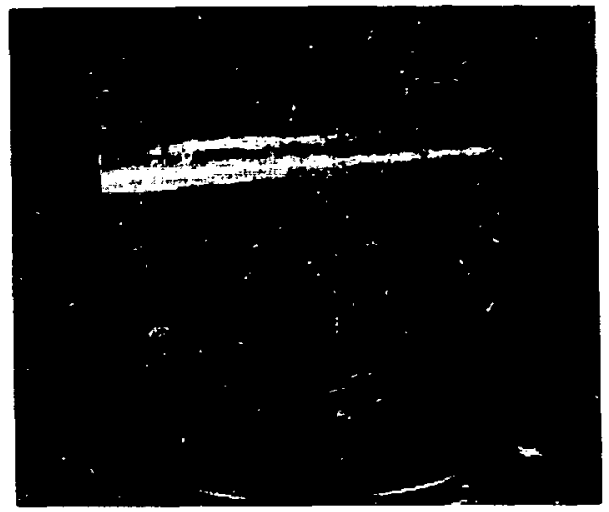

(a)

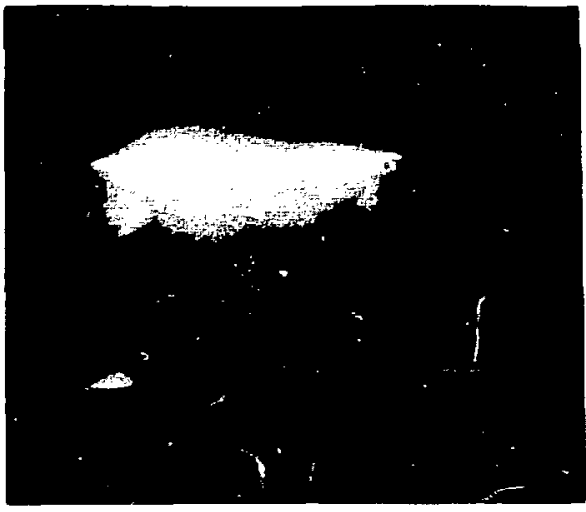

(b)

FIC. 4. A copper tee fitting photographed in configuration A by (a) combined neon gas glow and iluorescent light and (b) neon gas glow. Residue from hydrochloric acid cleaning accounts for the nonuniform, different-colored emission effects in (h).

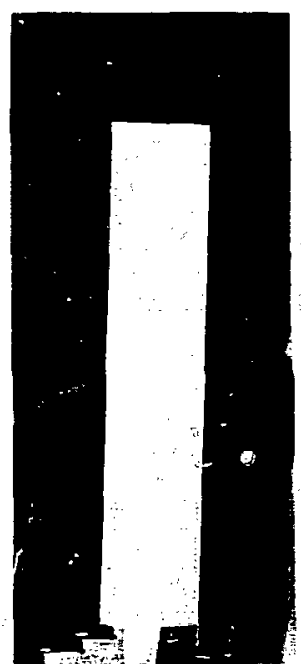

(a)

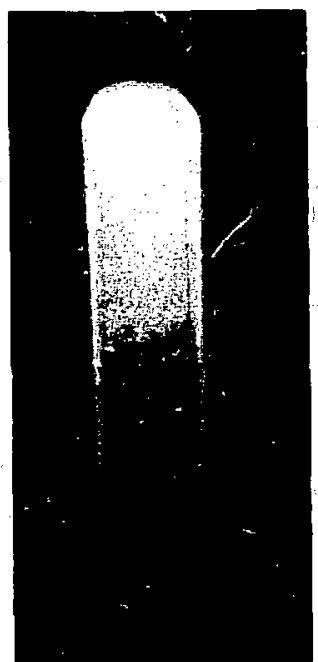

(b)

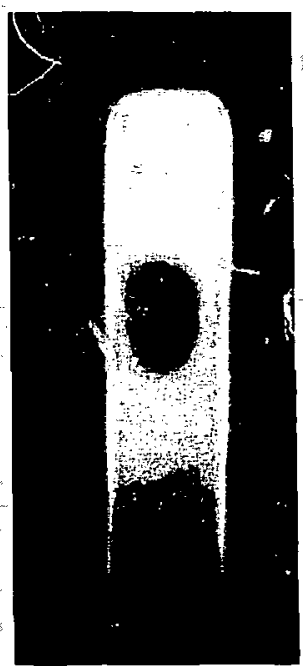

(c)

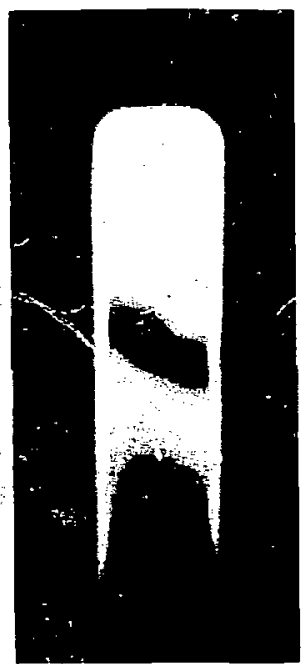

(d)

FIG. 5. A 4 by 30 by $200 \mathrm{~mm}$ aluminum prism in configuration $A$ and neon gas. The sequence of photographs shows (a) a clean prism by fluorescent room light, (b) a clean prism by the ionized gas flow, (c) emission changes from the residue left by a thumbprint, and (d) the opposite side of the prism where the index finger left a residue. Contaminations in (c) and (d) are not visible without the ionized gas. 
the unaided human eyc but were quite visible under ionization conditions.

Figure 6 shows a sequence of photographs taken in a transparent anode version of configuration B. The cathode is a 28-mm-diam aluminum round embedded with $3-\mathrm{mm}-$ and 1.5 mm-diam metal dises of higher and lower work lunction, respeclively, than the bulk material. One set of discs was made of the same material as the round to check on geometrical or machining effects. The specimen was fabricated by drilling the five 3-inm-diam holes equally spaced around a circle and the five 1.5 -mm-diam holes also equally spaced around a smaller circle. The purpose of the smaller holes was to reveal any size effects that might be present, but the location was probably more signifieant than size.

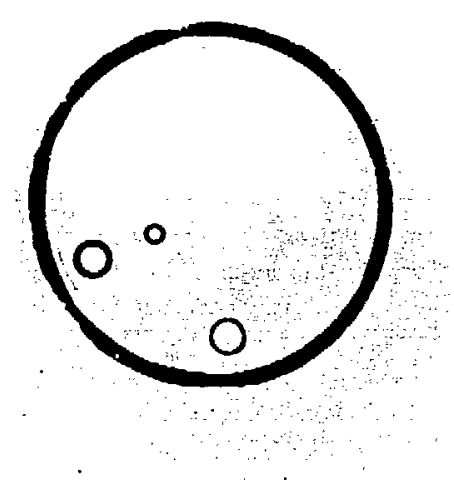

(a)

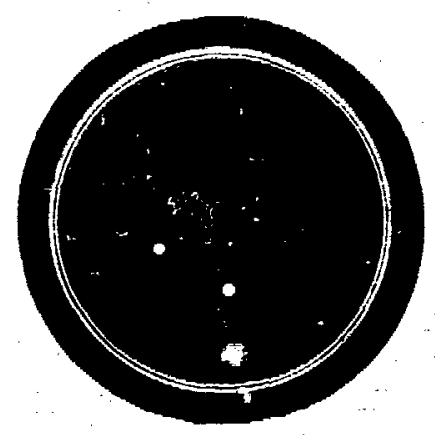

(c)

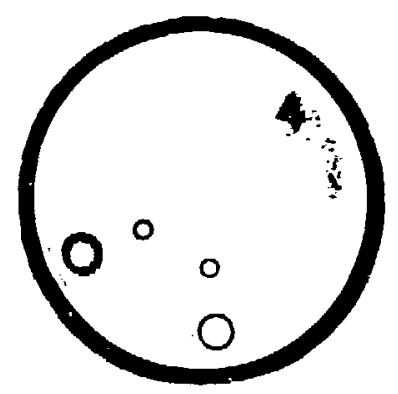

(b)

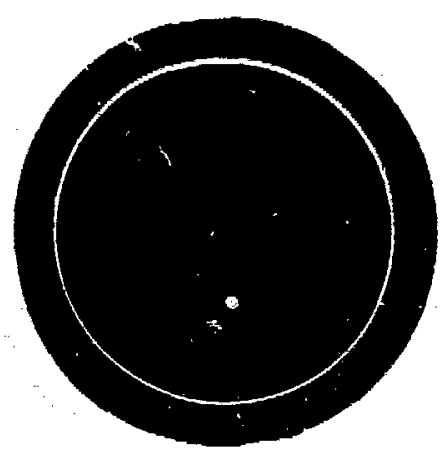

(d)

FG. 6. A 28-mm-diam AI round with round metal inserts that have various work functions. Taken in a transparent-anode version of configuration B, the ionization field photographs show (a) coronal discharge beginning for three inserts at $1.8 \mathrm{kV}$, (b) glow beginning opposite the four visible inserts at $2.2 \mathrm{kV}$, (c) glow everyw here except over the coronal sheaths at $3 \mathrm{kV}$, and (d) intense glow with a small area of coronal discharge at $4 \mathrm{kV}$. 
The 10 inserts were turned to proper diameter and inserted in the holes with a slight interference fil. The surface was then turned, leaving about a $0.25-\mathrm{mm}$ lip that prevents the intense outside edge corona from casting shadows on the inside surface. The common surface turning was intended to provide a surface geometry as uniform as possible.

The four photographs were taken at $3.35 \mathrm{kHz}$ at $1800,2200,3000$, and $4000 \mathrm{~V}$, respectively. In Fig. 6a, a set of materials has begun the breakdown process, as has the outside large-diameter insert of a second set. This is in addition to the outside edge, which a' "'ays breaks down first. Figure 6b shows that two cemplete sets have begun the discharge process, and the coronal intensity has increased. A small amount of glow is heginning opposite these sets. In Fig. 6c, the glow discharge has covered the surface except inside the coronal sheaths. The other two sets of different materials are visible, and microcorona outline the higher machine and polishing marks. In Fig. 6d, the glow has become more intense, illuminating the surface. Meanwhile, the microcorona has receded except in one area.

In the sequence, the outside edge corona discharge increases in intensity and size with the applied voltage. This is also true of the inside corona except that it grows inward to fiil the outlined cir- cles of its particular material. The visibility of the corona is well defined and usually of very high contrast. The glow is usually not well defined and tends to coat the electrode and provide a uniform surface illumination.

The sets of embedded materials with higher work functions have difterent colorations and are illuminated primarily by the glow discharge. Their optical images are a combination of cmission and normal illumination differences.

Note that corona discharge, because of its nonuniform fields, does not necessarily follow the work fur.ction series. The glow discharge, being uniform, does follow the thermionic (and field emission) series.

Because these experiments were performed in air, the electrode surfaces rapidly changed emissic characteristics and required resurfacing to repeat the sequence.

Figure $7 \mathrm{a}$ is a 13-mm-diam plated metal specimen illuminated by intense, single-source light at a very shallow angle of incidence. This lighting accentuates the machine marks by casting strong shadows. A mottled pattern r:? ught and dark is visible, as are some small plating defects. Figure $7 b$ is the same specimen in system B with transparent electrodes and atmospheric air pressure. The

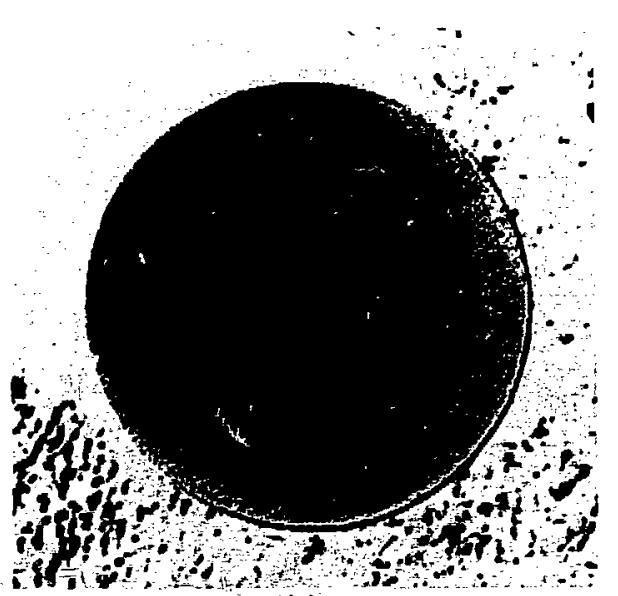

(a)

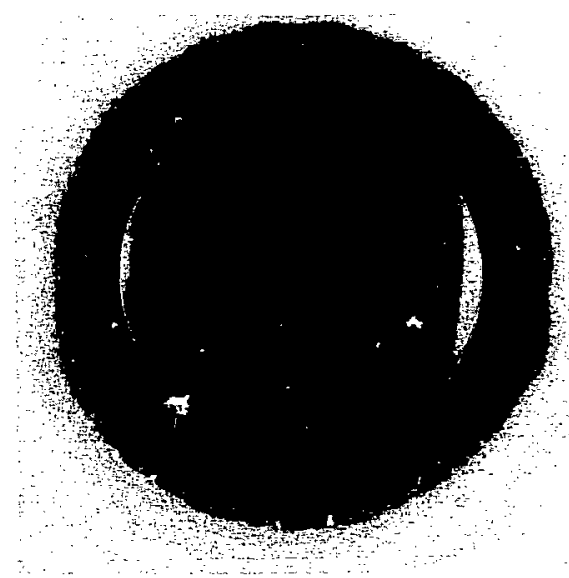

(b)

FIG. 7. A 13-mm-diam plated metal specimen. In (a), machine marks cast strong shadows from a single light source at a shallow angle of incidence. The marks are barely visible in (b), which was taken in a transparentelectrode version of configuration B, but a mottled pattern, characteristic of shrinking films on strong substrates, is more distinct. 

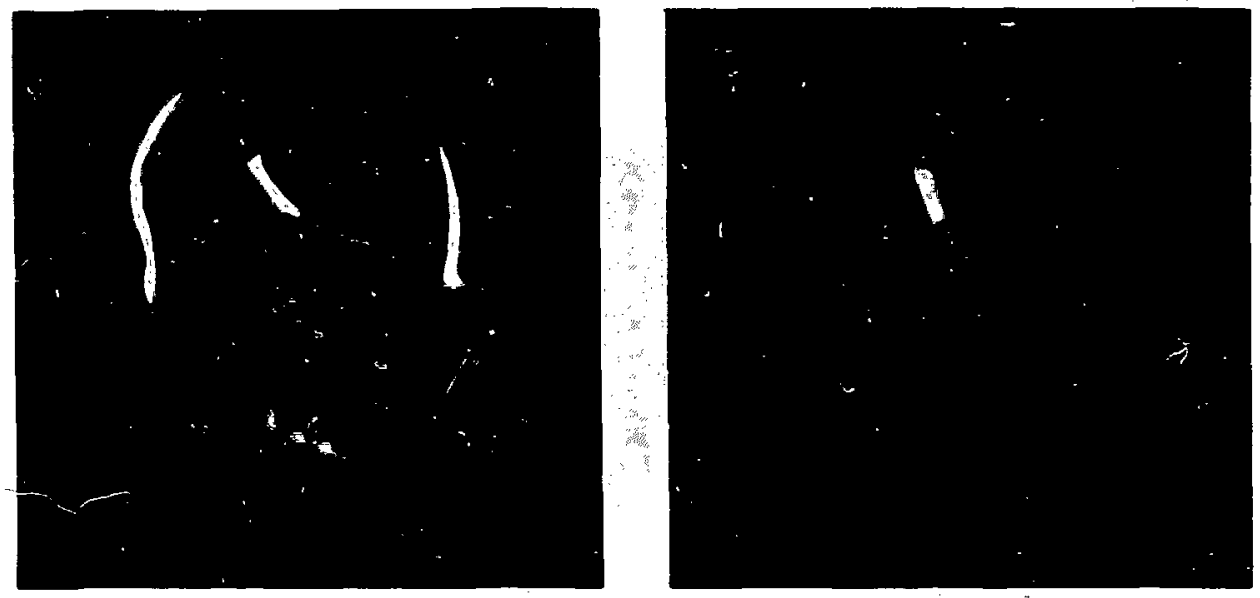

FIG. 8. Images of a small crescent wrench (photographed in configuration A by neon gas glow) show: glow concentrated on interior surfaces; a well-defined fingerprint; decreased emission effects from a band of paint on the handle.

machine marks have practically disappeared due to the more uniform surface illumination, and the mottled pattern is more distinct. The pattern resembles those characteristic of shrinking films on strong substrates. ${ }^{17}$ The uniformity of the pattern indicates a bond that is as strong as the chemical and metallurgical factors allow it to be. A poorly bonded specimen would exhibit a nonuniform pattern. This specimen is slightly curved, which accounts for the obvious edge effects.

Figure 8 shows two images of a small crescent wrench ( $10 \mathrm{~cm}$ long) taken in system $A$ using neon gas. These illustrate a number of phenomena previously discussed:

- The propensity of the glow discharge to concentrate on interior surfaces (geometry).

$\therefore$ - Accidental surface contamination of a welldefined fingerprint.

- Emission effects of an identifying band of paint on the upper handle.

Figure 9 also illustrates the tendency of the glow to fill or crawl into large cracks or fissures. Conditions are similar to those for Fig. 8. The bending-induced crack is open $\sim 1 \mathrm{~mm}$. The top portion of the 4 by 30 by $200 \mathrm{~mm}$ aluminum prism is coated by glow with the crack delineated by an intense horizontal line. Material factors that control this potential crack detector are not well known.
Figure 10a is a photograph of an electrical connector illuminated by fluorescent room light. The mated connector is about 2.5 by 7.5 by $20 \mathrm{~mm}$. Figure $10 \mathrm{~b}$ is the same connector photographed in system $A$ in neon gas. The left-hand spring clip could have plating, chemical-contamination, ant mechanical deformation problems. The mottled appearance of both spring clips is often characteristic of plastically deformed surfaces.

Figure 11 is an electrical image of a number of 5-mm-diam heat-treated stainless steel sleeves with an internal taper. Some are upside down with respect to the rest. Arrows point to two sleeves that show opposite anomalies, indications of probable metallurgical problems. The image was made by using configuration $B$ and direct exposure on color print paper in atmospheric pressure air. General heat treating problems were later confirmed by other means.

Figure $12 \mathrm{a}$ shows a variation of configuration A using the movable-dish, copper-mesh upper electrode. The subject is a welded bellows, $5 \mathrm{~cm}$ in diameter and $5.5 \mathrm{~cm}$ in length with limited interior access. A small (5-mm-diam) rod lens enters the chamber, passes through the mesh electrode, and extends into the bellows.

Figure 12b shows the same system with the bellows illuminated by ionized air. Note that the exterior welds are ciearly defined compared to the 


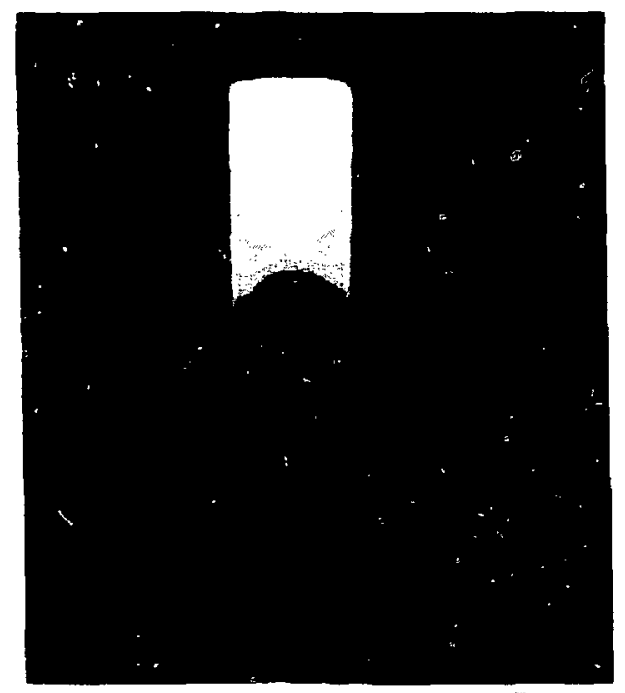

FIG. 9. Glow delineates a horizontal crack about I mm open induced by hending a 4 by 30 by $2001 \mathrm{~mm}$ aluminum prism.

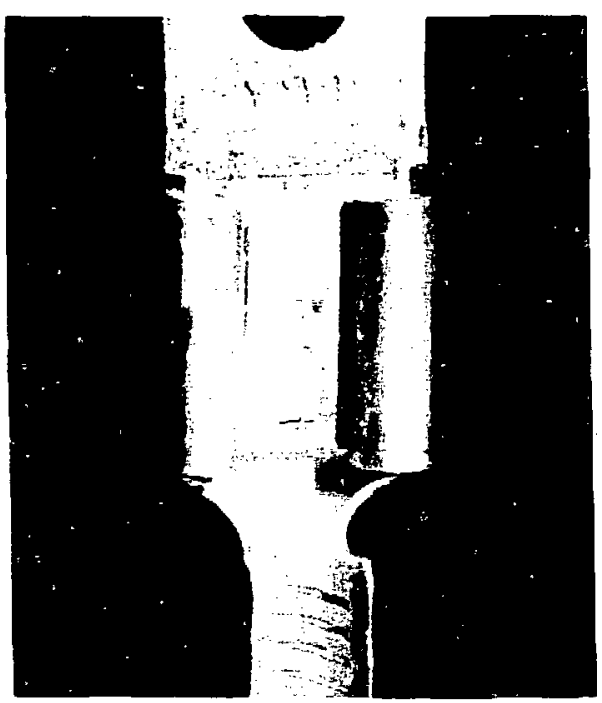

(a) room light photograph (Fig. 12it). The interior portions of the welds can be minutely examined through the rod lens.

Figure [2c shows the uniform light distribution even to the holtom of the bellows convolutions. For comparison, Fig. 12d is the same area illuminated with a single source, which produces deep shadows. lonized-gas illumination appears to have some advantages. ${ }^{\text {is }}$

In the use of configuration B there exist some solid dielectric elfects that should be noted. There is a relained charge in tine dielectric (Kodak slide glass) and even in the metal electrodes (probably the oxide coatings) that can interfere with subsequent images. These were first noticed as electrode (photographically recorded) images in the shapes of previously used clectrodes. These soon faded afier a few reionizations of shifted electrode position. Typical indications are shown in Fig. 13a, an electrical image of an internally-stepped 28 -mm-diam cylinder. Superimposed are the outli.es of four previously used electrodes, round and rectangular

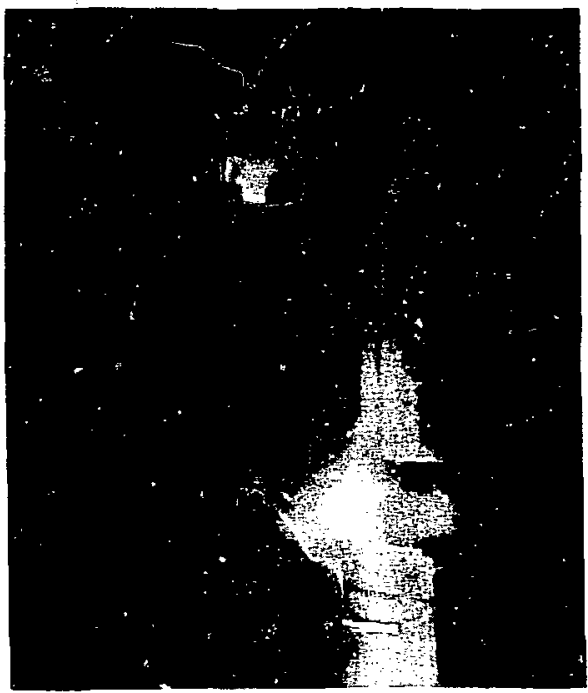

(b)

FIG. 10. An electrical connector phutographed in configuration $A$ by (a) fuorescent room light and (b) neon gas glow. The left-hand spring clip in (b) shows possible problems in plating, chemical contamination, mechanical deformation, or perhaps all three. Mottled patterns on the spring clips suggest plastic deformation of the surfaces. 


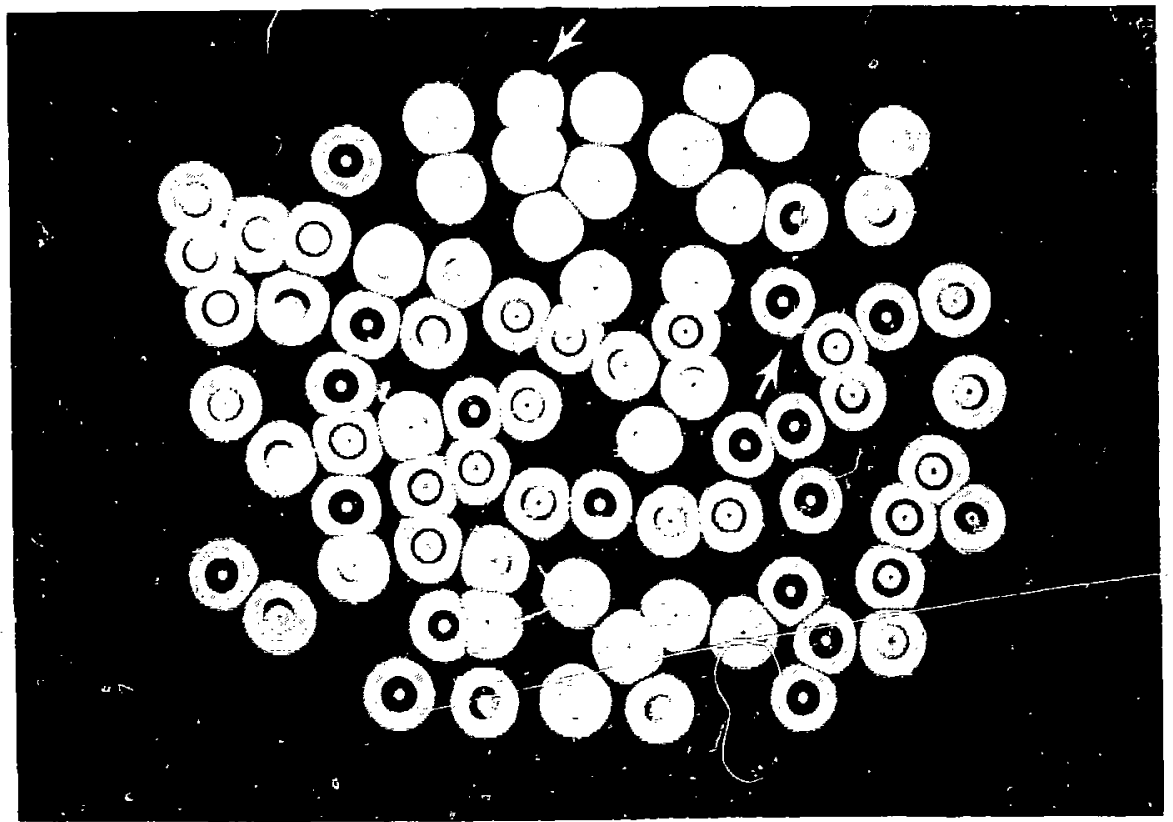

FIG. 11. A direct ionization image of 5-mm-diam heat-treated, stainless steel slecves with an internal taper reveals opposite anomalies (arrows) that were subsequently confirmed as the results of beat treating problems.

in shape. These were subsequently "erased" by repeated applications of the ionizing potential.

The breath-fogging technique (similar to cleaning eyeglasses) restored ali of the many "crased" electrode images in the dielectric. The hodgepodge (it's not a frog) shown in Fig. 13b is the resuit of using the breath-frgging technique on one such apparent!y clear i. 5 by 83 by $102 \mathrm{~mm}$ dielectric that had been used with a number of different electrodes. The moist hreath would not condense on the more highly charged areas of the glass dielectric.

Cleaning with nonconducting solvents did not remove the embedded charge. Conductive solutions (acids) iemporarily removed the effect, but the surface charge was soon replenished, apparently by the embedded eharge. The basic effect of the charge on airborne moisture may stem from surface tension modilications of the condensalte.

Figure 14 shows one of the previously discussed electrode configurations, the copper tee, but with thc addition of visible waves generated at the driving frequency within the electrode spacing and travelling in the ionized gas at a velocity determined by the gas characteristics. This effect is easily denonstrated by tuning the driving frequenct. This phenomenon suggested to us a possible use in reproducing ionization conditions for a given electrode configuration. By adjusting the system for a given velocity profile in the gas, we could aceurately recreate the conditions that produced the best results. 


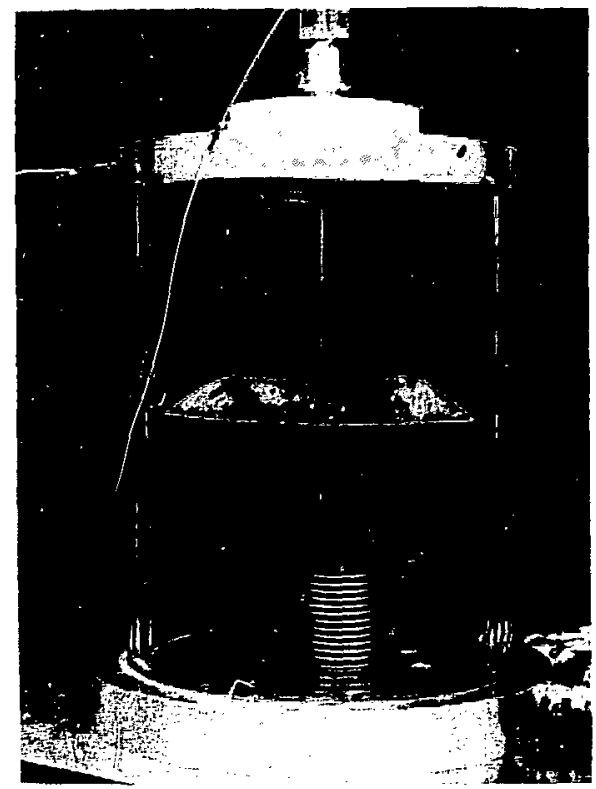

(a)

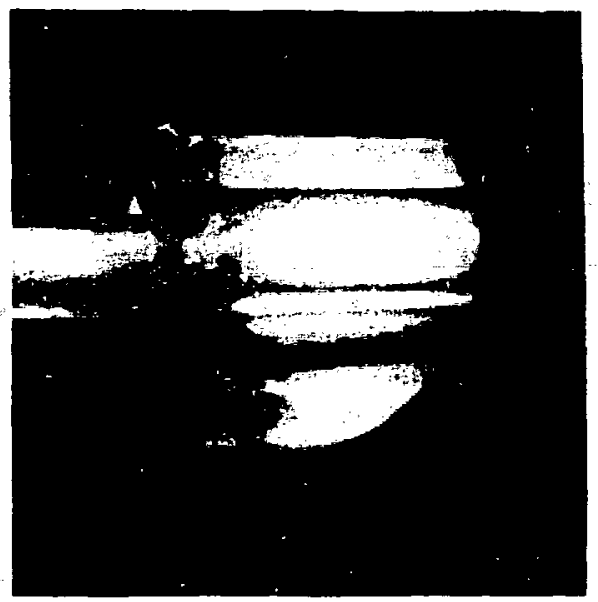

(c)

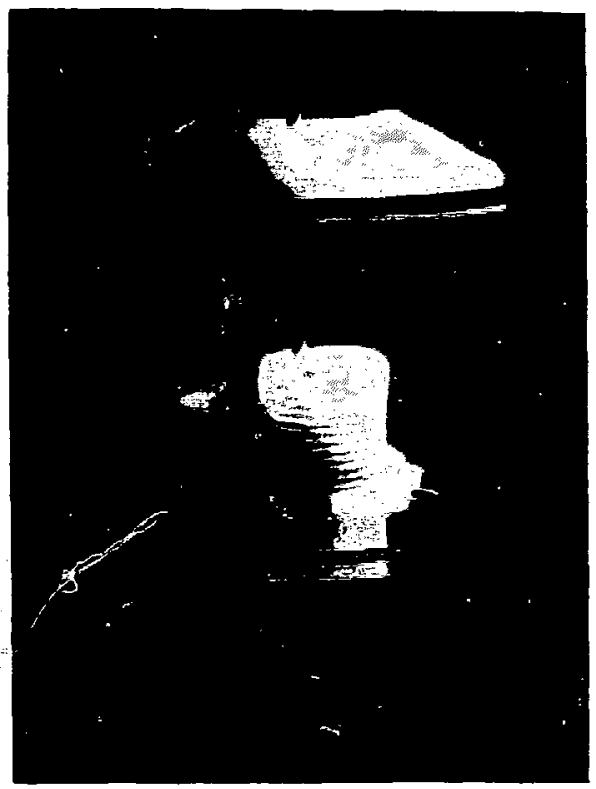

(b)

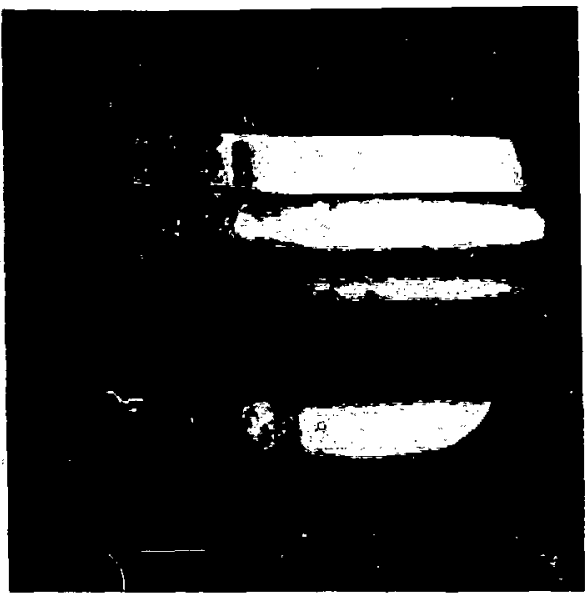

(d)

FIG. 12. A 5-cm-diam, 5-cm-long welded bellows is mounted in configuration $A$ and probed with a 5-mm-diam rod fens. The system is seen by (a) room light and (b) illuminated hy ionized air, which clearly reveals the exterior weld areas (dark lines in the center of light ridges). The uniform ionized-gas illumination of (b) is seen through the rod lens in (c) for interior weld areas and compared to the same weld area illuminated by a single conventional light source in (d). 


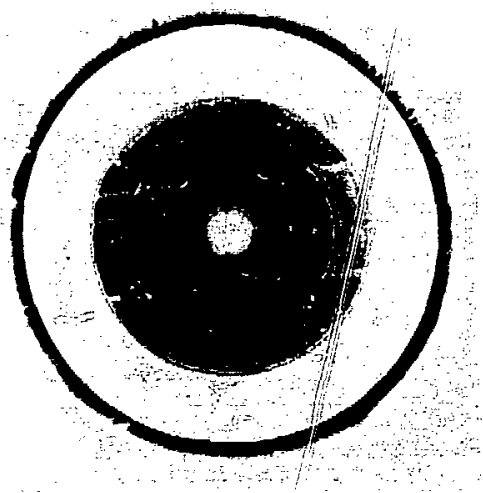

(a)

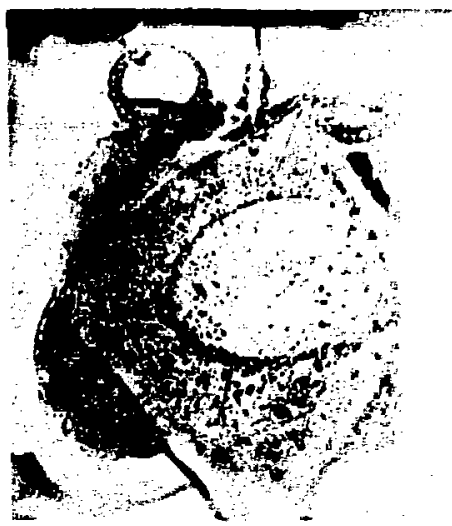

(b)

FIG. 13. The electrical image (a) of an internally-stepped 28-mm-diam cylinder also shows the images of several previousy used electrodes. Charge retention in the dielectric of configuration B is responsible for such ghost images, which can be "erased" by repeated applications of the ionizing patential. However, breath-fogging the dielectric temporarily restores all the images, as shown in (b).

FIG. 14. Visible standing waves generated within the electrode spacing of configuration $A$ using the copper tee as a cathode. Nonuniform spacing indicates variations in the ionized gas.

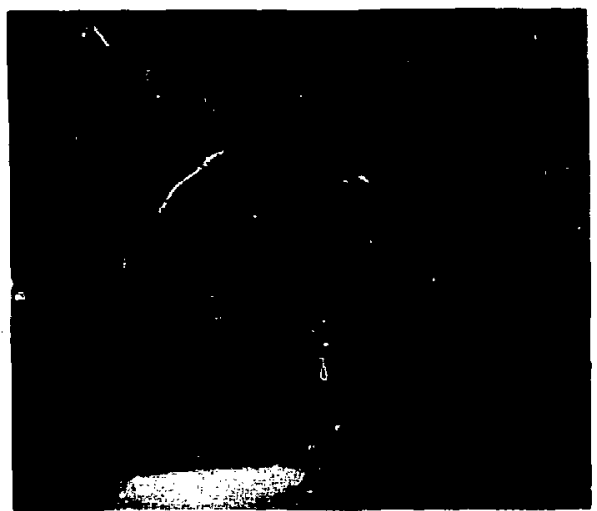




\section{CONCLUSIONS}

Though qualitative, electrical discharge in gases allows fast, economical screening of critical metal parts for anomalies. Though not easily analyzed, the observed effects can sometimes be linked to chemical, metallurgical, or mechanical caluses, or to a combination of them. Precise explanation of the anomalies is best left to other modern methods of scientific analysis in the context of process control.

The method can screen relatively large metal parts as well as large numbers of small parts. It is basically nondestructive and need not require sectioning of the part.

\section{ACKNOWLEDGMENT}

Gary W. Carter and Richard R. Petrini were major contributors to this effort. Dorin Van Lue provided the experimental fixturing. The project could not have begun and developed without the active and continued support of Riymond L. Morton. Richard G. Stone provided the resources of the
Engineering Research Program during the experimental phases, and Dennis Fisher allowed this report to be written under the auspices of the same program. I also wish to thank Ted Perlman for his critical, searching, and constructive review of this report. 


\section{REFERENCES}

1. J. Beynon, The Conduction of Electricity Through Gases (George G. Harrop Company, London, 1972).

2. E. Koffel and M. Abdullah, High-Voltage Engineering (Pergamon Press, London, 1966).

3. "Antireflection Coating for Plastic Lenses," NASA Tech. Briefs (Winter, 1976).

4. Techniques and Applications of Plasna Chemistry, J. R. Hollahan and A. T. Bell, Eds. (John Wiley and Sons, New York, 1974).

5. P. D. Townsend, J. C. Kelly, and N. E. W. Hartley, Ion Implantation, Sputtering and Their Applications (Academic Press, New York, 1976).

6. G. F. Buson, "A New Method of Nitrogen Case Hardening," jource Book on Nitriding (American Society for Metals, Metals Park, Ohio, 1977).

7. C. K. Jones, D. J. Sturges, and S. W. Martin, "Glnw Discharge N" Jing in Production," (1973) Source Book on Nitriding (A merican Sociely for Met: Metals Park, Ohio, 1977).

8. B. Edenhofer, "Production Ionitriding," (1976) Sour _ Boor on Nitriding (American Society for Metals, Metals Park, Ohio, 1977).

9. "Detecting Contamination on a Metal Surface," NASA Tech. Briefs (Winter, 1976).

10. "Detection of Surface Impurities on Processed Metals," NASA Tech. Briefs (Winter, 1976).

11. R. Haug and J. Lebas, (French)"Method for Plotting Work Function Distribution of a Thermionic Emitter," Rev. Sci. Instru. 44(9), (1973).

12. E. Ya Zandberg, A. Ya Ton tegode, and F. K. Yusifov, "The Utilization of a Combined Method of Thermoelectron Emission and Surface Ionization for the Study of the Emission Properties of Metallic Monocrystals and Film Emitters at Their Origin," Lawrence Livermore Laboratory, Livermore, CA., UCRL Translation 11219 (1977). From Structure and Properiies of Single Crystals of Refractory Metals, E. M. Savitskii, Ed. (Institut Metallurgii, Akademiye Navk USSR, Moscow, 1973), pp. 216-222.

13. A. R. C. Westwood and R. G. Lye,"Surfaces and Interfaces in Malerials Technology," Surfaces and Interfaces II, Proceedings of the 14th Sagamore Army Materials Research Conference 1967, J. J. Burke, N. Reed, and V. Weiss, Eds. (Syracuse University Press, 1968).

14. J. K. Stanley, Electrical and Magnetic Properties of Metals (American Society for Metals, Metals Park, Ohio, 1963).

15. F. C. Tompkins, Chemisorption of Gases on Metals (Academic Press, 1978).

16. J. C. Grosskreutz and D. K. Benson,"The Effects of the Surface on the Mechanical Properties of Metals," Surfaces and Interfaces II. Proceedings of the I4th Sagamore Army Materials Research Conference 1967, J. J. Burke, N. Reed, and V. Weiss, Eds. (Syracuse University Press, 1968).

17. P. S. Ste!ens, Patterns in Nature (Atlantic Monthly Press, Little, Brown and Co., 1974).

18. D. E. Lord, R. R. Petrini, and G. W. Carter, Examination of Interior Surfaces Using Glow-Discharge Illumination, U.S. Patent 4,102,582 (July 25, 1978).

$\mathrm{RJ} / \mathrm{ml}$ 